\title{
Evaluating Driving Performance of Outpatients with Alzheimer Disease
}

\author{
Daniel J. Cox, PbD, Warren C. Quillian, Frances P. Thorndike, Boris P. Kovatchev, PbD, \\ and George Hanna, MD
}

Background: Alzheimer disease (AD) is a progressive disease, with multiple physiologic, psychologic, and social implications. A critical issue in its management is when to recommend restrictions on autonomous functioning, such as driving an automobile. This study evaluates driving performance of patients with AD and its relation to patient scores on the Mini-Mental State Exam (MMSE).

Methods: This study compared 29 outpatients with probable AD with 21 age-matched control participants on an interactive driving simulator to determine how the two groups differed and how such differences related to mental status.

Results: Patients with AD (1) were less likely to comprehend and operate the simulator cognitively, (2) drove off the road more often, (3) spent more time driving considerably slower than the posted speed limit, (4) spent less time driving faster than the speed limit, (5) applied less brake pressure in stop zones, (6) spent more time negotiating left turns, and (7) drove more poorly overall. There were no observed differences between $\mathrm{AD}$ patients and the control group in terms of crossing the midline and driving speed variability. Among the $\mathrm{AD}$ patients, those who could not drive the simulator because of confusion and disorientation $(n=10)$ had lower MMSE scores and drove fewer miles annually. Those AD patients who had stopped driving also scored lower on their MMSE but did not perform more poorly on the driving simulator.

Factor analysis revealed five driving factors associated with $\mathrm{AD}$, explaining 93 percent of the variance. These five factors correctly classified 27 ( 85 percent) of $32 \mathrm{AD}$ patients compared with the control group. of the 15 percent who were improperly classified, there were three false positives (control participants misclassified as AD patients) and two false negatives (AD patients misclassified as control participants). The computed total driving score correlated significantly with MMSE scores $(r=-.403, P=0.011)$.

Conclusion: Driving simulators can provide an objective means of assessing driving safety. (J Am Board Fam Pract 1998;11:264-71.)

It has been estimated that Alzheimer disease (AD) affects more than 10 percent of all persons aged 65 years and older and almost 50 percent of all adults older than 85 years. ${ }^{1}$ Because the population is aging, the rate of $A D$ in the United States is expected to rise considerably. Persons with $\mathrm{AD}$ have a variety of deficits in memory, visual attention, perception, judgment, and other cognitive functions, ${ }^{2-5}$

Submitted, revised, 1 October 1997.

From the Department of Psychiatric Medicine (DJC, WCD, FPT, BPK) and Department of Neurology (GH), University of Virginia Health Sciences Center, Charlottesville, Va. Address reprint requests to Daniel J. Cox, PhD, Box 223, University of Virginia Health Sciences Center, Charlottesville, VA 22908.

This study was supported in part by grants from the Virginia Alzheimer's and Related Diseases Association, American Automobile Association of Highway Safety, Association For The Advancement of Retired Persons, and the National Institute of Health (RO128288). all of which are necessary components of safe driving, and deficits in these areas have been shown to result in impaired driving ability.,6-16 Since studies have implicated $\mathrm{AD}$ with an increased risk of accidents, ${ }^{17-21}$ persons with $\mathrm{AD}$ who continue to drive could be putting themselves and others at risk.

Although surveys have not determined the number of persons with $\mathrm{AD}$ who drive, it is believed to be a common and important public health concern. ${ }^{20}$ Almost 60 percent of drivers with $\mathrm{AD}$ continued to drive until they were involved in an accident. ${ }^{15}$ Autopsies of elderly drivers involved in fatal accidents have found evidence of $\mathrm{AD}$ or early-stage $\mathrm{AD}$ in nearly 50 percent of the cases studied. ${ }^{22}$ Despite the apparent dangers, many $\mathrm{AD}$ patients continue to drive for 3 to 4 years following diagnosis, ${ }^{13}$ even after having had an accident. ${ }^{16}$ 
A critical issue for clinicians is to decide when it is appropriate to prevent further operation of a motor vehicle. Physicians face difficult ethical dilemmas when making this determination. In some states, physicians are required by law to report unsafe drivers. ${ }^{23-29}$ Although few physicians actually report their patients to their departments of motor vehicles, many might feel that determining driving fitness is a physician's responsibility. Although family members might encourage the clinician to remove the patient's driver's license, patients often plead with their physicians to allow them to keep their licenses. Often spouses, even though concerned about safety, support continued licensing because they depend on the patient's driving. This situation strains the physician-patient relationship because the decision to terminate a patient's driving is subjective. Thus, a critical area for investigation is determining at what point driving ability becomes so impaired that the patient should no longer drive.

Because standardized neuropsychologic tests have not proved to be sufficiently sensitive and specific for the purpose of determining driving fitness, ${ }^{30}$ some believe clinicians should refer their $\mathrm{AD}$ patients to local departments of motor vehicles for further on-road testing. Using improved performance-based on-road tests, recent studies have documented driving impairments in people with $\mathrm{AD} .{ }^{31} \mathrm{~A}$ major limitation with any road test, however, is that patients cannot be exposed to high-risk, nonroutine driving demands to determine the quickness and appropriateness of their judgment and subsequent execution of driving maneuvers. Although some drivers might be able to perform adequately under routine conditions and pass the on-road test, some driving impairments might express themselves only during nonroutine, high-risk situations.

Ideally, $\mathrm{AD}$ patients could be monitored closely and then, when appropriate, have their license revoked when they become unfit to drive, but there has been no realistic way to quantify objectively their fitness to drive. A major barrier to assessing driving performance has been the absence of a driving simulator that presents realistic driving experiences. Such experiences should require the driver to negotiate routine traffic demands as well as have the driver encounter high-risk situations that assess the ability to control the vehicle and avoid accidents appropriately.
The Atari driving simulator ${ }^{32}$ is a sophisticated, realistic research tool capable of addressing these issues. An earlier single-screen version of this simulator effectively detected the acute effects of hypoglycemia ( $45 \mathrm{mg} / \mathrm{dL}$ ) among patients with type 1 diabetes, ${ }^{33}$ which was reliable for more than 3 months, ${ }^{34}$ and legal intoxication ( $\geq 0.08$ percent blood alcohol level) among college students. ${ }^{35}$ The current three-screen version of the simulator has been used to (1) differentiate middle-aged from elderly male drivers when sober and legally intoxicated, ${ }^{36}$ (2) differentiate visually compromised drivers from control drivers, ${ }^{37-42}$ and (3) correlate simulator performance with age-sensitive cognitive characteristics. ${ }^{42}$ Not only has the Atari simulator detected high-risk groups, but results from the simulator correlate with both onroad test results (Guerrier J, Cox DJ, unpublished research, 1997] and parallel common driving errors among the elderly. ${ }^{43}$

In the current study we used the more sophisticated version of this interactive computer technology to evaluate driving performance of age-matched adults with and without probable $\mathrm{AD}$. The following questions were examined:

1. Does performance on the Atari driving simulator differentiate $\mathrm{AD}$ patients from the control group matched by age and socioeconomic status?

2. Does simulator performance differentiate $\mathrm{AD}$ patients who have stopped driving from patients who are still driving?

3. Does simulator performance correlate with the Mini-Mental State Exam (MMSE) ${ }^{44}$ scores, a well-established general field measure of dementia?

\section{Methods}

Twenty-nine adults who satisfied Diagnostic and Statistical Manual of Mental Disorders, 3rd edition, Revised (DSM-III-R) ${ }^{45}$ criteria for probable AD were recruited from a sample of outpatients participating in AD drug protocols in the Department of Neurology at the University of Virginia Hospital. All patients who came to the hospital for a drug study screening appointment during an 8month period were asked to participate in the current study before beginning the drug protocol. To be included in the study, the patients had to be older than 55 years, meet the DSM-III-R criteria for probable $\mathrm{AD}$ for a minimum of 6 months' du- 
Table 1. Mean and Standard Deviations of Descriptive Characteristics of Alzheimer Disease Patients and Control Participants with Contrast $P$ Values.

\begin{tabular}{lccc}
\hline Variable & $\begin{array}{c}\text { Alzheimer Disease } \\
\text { Patients }(\mathrm{n}=29)\end{array}$ & $\begin{array}{c}\text { Control Participants } \\
(\mathrm{n}=21)\end{array}$ & $P$ Value \\
\hline Sex, \% male & 45 & 62 & 0.24 \\
Age, $y$ & $72.0 \pm 8.6$ & $70.1 \pm 10.0$ & 0.571 \\
Education, $\mathrm{y}$ & $14.1 \pm 3.5$ & $15.8 \pm 3.5$ & 0.119 \\
Years as licensed driver & $53.9 \pm 9.1$ & $51.9 \pm 0.5$ & 0.549 \\
Active driver's license, \% (n) & $93(27)$ & $100(21)$ & 0.26 \\
Current driver, \% (n) & $59(17)$ & $100(21)$ & 0.002 \\
Average miles driven per year & $3957 \pm 6662$ & $6223 \pm 4671$ & 0.16 \\
Self-reported accidents per 1 million miles driven, average $\mathrm{n}$ & $9.8 \pm 36$ & $8.0 \pm 28$ & 0.9 \\
Self-reported moving violations per 1 million miles driven, average $\mathrm{n}$ & $15.1 \pm 60$ & $3.2 \pm 10$ & 0.40 \\
Could not complete the driving test, simulator sickness, \% (n) & $7(2)$ & $24(5)$ & 0.09 \\
Could not complete the driving test, cognitive impairment, \% (n) & $34(10)$ & $0(0)$ & 0.003 \\
Mini-Mental State Exam score & $21.2 \pm 4.6$ & $28.7 \pm 9.6$ & $<0.0001$ \\
\hline
\end{tabular}

ration, and have a responsible spouse or caregiver able to participate. Patients who had other medical conditions that could affect driving performance or those taking medications that could impair driving performance were excluded based on their physician's determination.

Although patients were assured that participating in the study would not affect their licensing, some still chose not to participate because they feared that having hospital employees observe their driving might result in the loss of their license. Spouses or caregivers of the AD patients were also asked to participate in the study as control participants. These control participants were also 55 years of age and older and currently driv-

Table 2. Frequency of Driving Demands for 8-Mile Experimental Study Course.

\begin{tabular}{lc}
\hline Driving Demand & Frequency \\
\hline $\begin{array}{l}\text { Left turns - driver needs to turn left at specific } \\
\text { stop-sign intersections, negotiating oncoming }\end{array}$ & 3 \\
$\begin{array}{l}\text { and cross traffic } \\
\text { Red lights - driver needs to stop }\end{array}$ & 2 \\
Green lights - driver has throughway & 4 \\
Stop signs - driver needs to stop & 6 \\
Throughway stop-sign intersections - & 4 \\
side-traffic stops & 11 \\
Speed limit changes - driver needs to change speeds & 11 \\
Sudden stops - car in front of driver slams on brakes, & 3 \\
object in road comes into view as driver crosses & \\
hillcrest, car runs red light from left side & \\
Detours at stop-sign intersections - driver needs to & 4 \\
$\quad$ obey detour arrow & 1 \\
Encroaching fixed objects - vehicle parked in & \\
$\quad$ driver's lane &
\end{tabular}

ing. As shown in Table 1, those in the control group were similar to $\mathrm{AD}$ patients in terms of sex distribution, age, education, years licensed, and average miles driven per year. The control group scored considerably better on the MMSE.

\section{Instruments}

Three instruments were used in this study: (1) a background and driving-history questionnaire, (2) the MMSE, and (3) the Atari driving simulator. The MMSE was used to measure dementia severity on a range of scores from 0 to 30 . Generally, scores of 28 to 30 are considered normal, 21 to 27 suggest mild dementia, 11 to 20 , moderate dementia, and 0 to 10 , severe dementia. ${ }^{44}$

The Atari driving simulator has three 25 -inch computer screens that wrap around the driver, providing a 165-degree visual field, and a programmed rearview mirror depicting rear traffic. While the center screen presents the front windshield display, the two adjacent side screens display side views of traffic and road conditions. The driving environment was realistic, incorporating a typical-sized steering wheel, gas and brake pedals, seat, and seat belt. Driving performance feedback was provided visually through the three screens that updated at a rate of 60 times per second, auditorily through quadraphonic speakers, and kinesthetically through the steering wheel and pedal pressure.

The experimental driving course was approximately 8 miles and was designed to simulate driving demands of a typical grade 2 US highway (Vir- 
Table 3. Driving Performance Variables and Explanations.

\begin{tabular}{|c|c|}
\hline Driving Variable & Driving Variable Explanation \\
\hline \multicolumn{2}{|l|}{ Steering variables } \\
\hline SD steering & Standard deviation of stecring wheel rotation \\
\hline Off road & Number of times car travels off road \\
\hline Risk midline & Quadratic risk function that increases the longer and farther the car crosses the midline \\
\hline \multicolumn{2}{|r|}{ S } \\
\hline Full stops & Percentage of appropriate complete stops negotiated at stop signs and stoplights \\
\hline Missed stops & Percentage of times at stop signs and red lights minimum speed was $>5 \mathrm{mph}$ \\
\hline Maximum brake & Maximum brake pressure applied in stop zones \\
\hline Bump collisions & Percentage of times driver in accident traveling $<20 \mathrm{mph}$ \\
\hline \multicolumn{2}{|l|}{ Speed variables } \\
\hline Low speed & Average percentage below speed limit when car is in $35 \mathrm{mph}$ and $45 \mathrm{mph}$ speed zones \\
\hline High speed & Average percentage above speed limit when car is in $35 \mathrm{mph}$ and $45 \mathrm{mph}$ speed zones \\
\hline SD speed & Standard deviation of speed in 35 and $45 \mathrm{mph}$ zones \\
\hline Stop sign hesitation & Average time spent stopped at stop sign \\
\hline Left turning time & Seconds required to go from complete stop at the stop line to complete the left turn \\
\hline
\end{tabular}

SD - Standard deviation.

ginia Department of Transportation). Table 2 lists the demands of the course.

The simulator recorded data eight times a second and generated the 12 driving performance variables listed in Table 3. Because different participants completed different percentages of the course, and because the farther the participants drove, the more likely they were to encounter a critical event, full stops, missed stops, and collisions were calculated according to the percentage of the course completed for each driver. To incorporate two variables, such as time and speed or time and distance, quadratic functions were calculated for risk midline, low speed, and high speed.

\section{Procedure}

AD outpatients in the University of Virginia Department of Neurology drug protocols went through an initial 2-week baseline period before being given medications. During the baseline period, study participants signed an informed consent form and completed the background and driving history questionnaire. To validate patients' report of a recent accident and violation, spouses or caregivers completed the pertinent questionnaire concerning these issues. Next, the study participants were administered the MMSE. Study participants were then verbally oriented to the simulator before driving a standardized practice course.

The practice course was similar to the experimental study course, but there were fewer road signals and less traffic. During the practice course, room lighting was adjusted to the driver's preference to minimize glare on the monitors. Once drivers completed the practice course, they were allowed to continue driving until they felt fully comfortable operating the simulator. They next drove the experimental study course, which took approximately 20 minutes to complete. If the participants experienced simulator sickness (nausea and dizziness) or cognitively could not comprehend the operations of the simulator during the practice trial, the driving test was discontinued.

\section{Results}

Compared with the control group, $\mathrm{AD}$ patients were less likely to be current drivers (59 vs 100 percent, $z=3.1, P<0.002$ ), had lower MMSE scores $(21.2 \pm 5.0$ vs $28.7 \pm 1.0, t=5.1, P<0.001)$, and were less able to complete the driving test because of confusion or disorientation (34 vs 0 percent, $z=0.0, P<0.003$ ). No differences were observed between groups in terms of age, sex, education, years licensed, valid license status, miles driven per year, or number of self-reported moving violations ( 15 vs 3 ) or accidents in the past 5 years per 1 million miles driven (Table 1 ).

Among the AD patients, those who were unable to drive the simulator because of confusion or disorientation differed from those who were able to drive in terms of lower MMSE scores (19.6 \pm 5.0 vs $22.5 \pm 4.0, t=2.0, P<0.05)$ and drove fewer miles annually $(2350 \pm 3597$ vs $4855 \pm 8200, t=$ $3.2, P<0.005)$. Similarly, AD patients who were not currently driving differed from currently dri- 

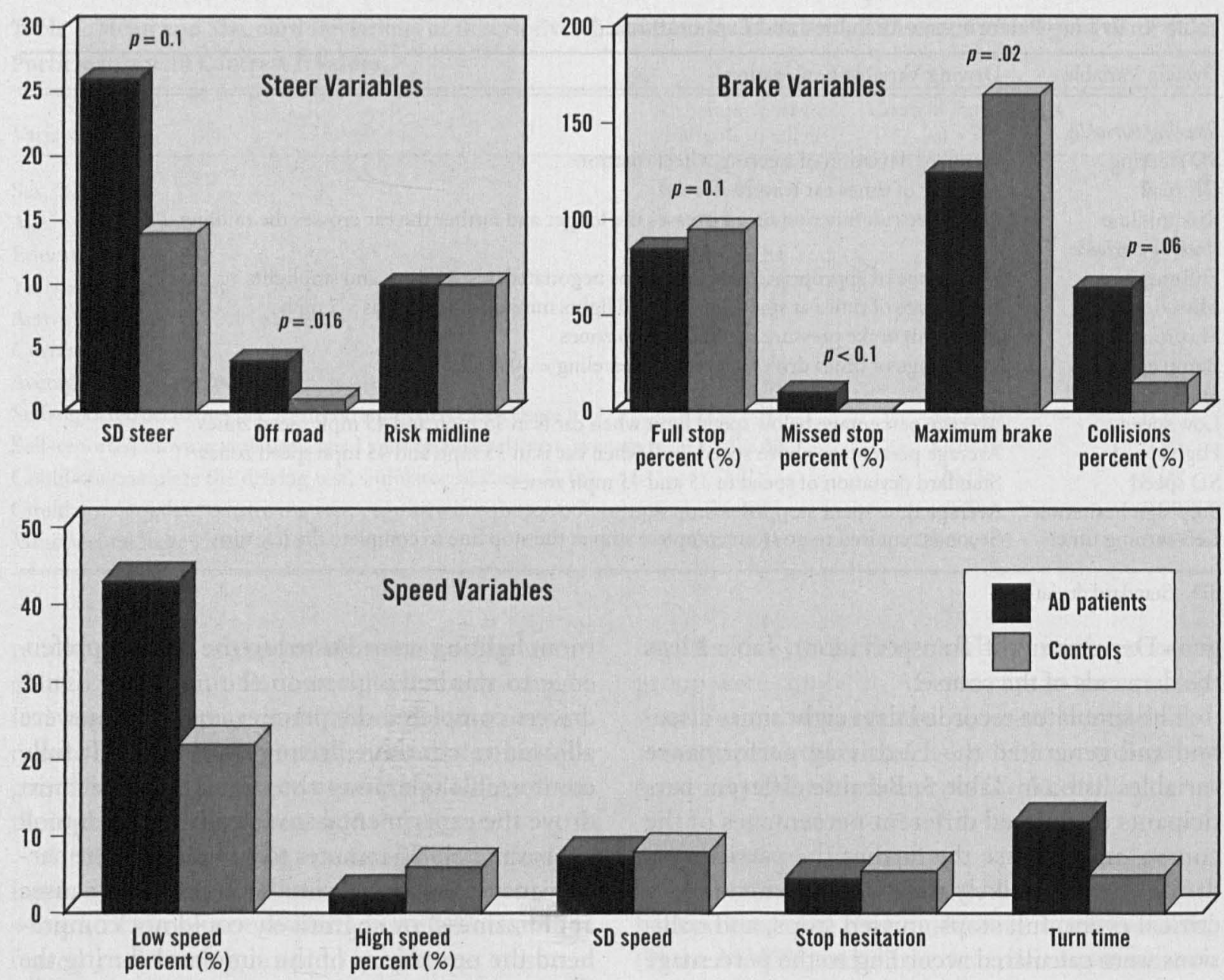

Figure 1. Comparison of Alzheimer disease patients and control participants on steering, braking, and speed variables. SD - standard deviation

ving $\mathrm{AD}$ patients only in terms of a lower MMSE score $(19.4 \pm 5.0$ vs $22.5 \pm 4.0, t=2.3, P<0.05)$.

\section{Driving Performance}

To assess driving performance, we could only analyze data from those who were able to drive the simulator $(\mathbf{n}=17)$. Consequently, relevant driving data were not generated for anyone experiencing simulator sickness $(\mathrm{n}=2)$ or who were cognitively unable to perform the driving task $(n=10)$. The 17 remaining $\mathrm{AD}$ patients performed more poorly on the simulator than those in the control group. AD patients went off the road more often $(t=$ $2.55, P=0.016)$, drove slower $(t=4.08, P<0.001)$, spent less time driving above the speed limit $(t=$ 2.2, $P=0.040$, completed less of the course $(t=$ $3.7, P<0.001)$, applied less brake pressure in stop zones $(t=2.33, P=.027)$, and spent more time negotiating left-turns $(t=2.75, P<0.048)$.
Although not statistically significant ( $P$ values ranging from 0.05 to 0.10 ), several trends emerged that further differentiated $\mathrm{AD}$ patients from the control group. $\mathrm{AD}$ patients had greater steering wheel variability $(t=1.56, P=0.10)$, made fewer full stops $(t=1.65, P=0.10)$, missed more stops ( $t=1.74, P=0.1)$, spent less time waiting at stop signs $(t=1.77, P=0.09)$, and had more collisions $(t=2.04, P=0.06)$ (Figure 1).

There were no observed differences between $\mathrm{AD}$ patients and those in the control group in terms of crossing the midline $(t=0.13, P=0.9)$ or speed variability $(t=0.57, P=0.68)$. Additionally, no differences were observed on the simulator between $\mathrm{AD}$ patients who were currently driving and those who were not currently driving (all, $P>0.3$ ).

To distinguish the driving factors associated with $A D$, we used the following nine significant driving performance variables in a factor analysis: 
Table 4. Driving Factors Associated With Alzheimer Disease and Degree of Variance for Each Factor.

\begin{tabular}{llc}
\hline Factor & Driving Variables & Degrec of Variance, Percent \\
\hline Poor steering control & SD steering, off road, collisions & 38.1 \\
Poor stopping control & Full stops, missed stops & 24.0 \\
Speed control & Low speed, high speed & 16.0 \\
Weak braking & Maximum braking & 9.7 \\
Improper braking & Inappropriate braking & 5.1 \\
Total & & 92.9 \\
\hline
\end{tabular}

SD - standard deviation.

standard deviation of steering wheel rotation, off road, inappropriate braking, low speed, high speed, full stops, missed stops, maximum braking, and collisions. Because 5 participants never reached a left-turn stop sign, the stop sign hesitation and left turning time variables were omitted from this analysis to avoid any missing data. $z$ Scores were computed for all variables to ensure that variables were of comparable size. Five factors extracted from the variables explain 92.9 percent of the variance. Table 4 lists these factors and shows the degree of variance for each factor.

A logistic regression based on the five factors (poor steering control, poor stopping control, speed control, weak braking, and improper braking) accurately classified 27 of 32 ( 85 percent) of the participants as $\mathrm{AD}$ patients. Of the 15 percent who were inaccurately classified, 3 were false positives (control participants misclassified as $\mathrm{AD}$ patients) and 2 were false (AD patients misclassified as control participants).

Next, we computed a total driving score based on the same five factors, with a lower total score indicating better driving performance. The total driving scores correlated significantly with the MMSE scores $(r=-.403, P=0.011)$. We could also use this total driving score for additional comparisons of driving performance between currently driving $\mathrm{AD}$ patients and currently nondriving $\mathrm{AD}$ patients and control participants. Using the total driving score, we consequently conducted a $1 \times 3$ multiple analysis of variance with planned contrasts. AD patients (current drivers and nondrivers) performed significantly worse than control participants $(t=4.4, P<0.001)$. Similarly, currently driving $\mathrm{AD}$ patients performed worse than control participants $(t=3.4, P=0.002)$. Among the $\mathrm{AD}$ patients, currently driving patients did not perform differently from patients currently not driving $(t=0.86, P=0.394)$.

\section{Discussion}

Driving simulator performance was able to differentiate $A D$ patients from control participants and correlated with MMSE scores; those who could not drive the simulator had significantly lower MMSE scores. Specifically, these results suggest that, in general, patients with $\mathrm{AD}$ do not drive across the midline more often; instead, they drive off the side of the road significantly more often, possibly as a compensatory response. An additional possible compensatory response was to drive slowly, both on the open road (low speed) and while turning left (left turning time), which was further verified by the observation that $A D$ patients spent less time speeding (high speed) than control participants. Although these strategies might allow AD drivers more time to process information and react, it puts them at greater risk of being hit, especially when turning left and crossing through three lanes of traffic. That 62 percent of $\mathrm{AD}$ patients were involved in possible crashes, compared with 15 percent of control participants, suggests such compensatory strategies are ineffectual.

The wide difference in collision rate ( 62 versus 15 percent) between $\mathrm{AD}$ patients and the control group does not reach significance $(P=0.06)$ in part because of the great variation among $A D$ drivers. Standard deviations for $A D$ and control participants were 100 and 15 , respectively, which suggests that all $\mathrm{AD}$ drivers are not high risk. That some $A D$ patients might be safe drivers is further suggested by the regression analysis, which misclassified $2 \mathrm{AD}$ drivers as control participants (false negatives). These 2 patients might have been safe drivers, as suggested by MMSE scores of 28 and 22 , and total driving scores of -1.5 and -1.4 . The implication is that the mere diagnosis of early-stage $A D$ does not necessarily equate with poor driving risk. 
It was also noteworthy that $\mathrm{AD}$ patients who had stopped driving did not drive the simulator more poorly. This finding suggests that either the simulator does not discriminate between good and poor drivers with $\mathrm{AD}$ or that the $\mathrm{AD}$ driver's decision to continue driving was not based on actual ability to drive.

Thus driving simulators could have clinical utility in determining a person's driving fitness. It appears to be a sensitive instrument, correctly classifying 85 percent of $\mathrm{AD}$ patients. It also singled out $10 \mathrm{AD}$ patients who could not even complete the course as a result of confusion and cognitive impairments. Because the driving simulator results correlate well with MMSE scores, this quick examination can be used as an early screening tool.

$\mathrm{AD}$ is a complex disease process that affects people physically, psychologically, and socially in diverse ways. Even so, we were able to find five driving performance factors that explained 93 percent of the outcome variance. Perhaps this progressive disease process affects people more homogeneously than previously thought, at least in terms of driving performance. Although AD can ultimately impair driving performance in similar ways, a continuum of safe driving exists, and $\mathrm{AD}$ drivers will eventually reach an unsafe threshold. Blanket restrictions based on diagnosis alone, however, such as those suggested by Barrett et al, ${ }^{7}$ might be too severe.

That these findings are from a relatively small, select sample of willing patients and caregivers might limit generalization. Nevertheless, the findings justify further studying patients with $\mathrm{AD}$ on interactive driving simulators. Until standardized simulation testing is widely available, the physician is left to determine fitness to drive based on clinical findings. Our study findings suggest that restricting driving should not be based either on the patient's diagnosis or willingness to drive. Instead, the MMSE and reliable reports of how attentive and reactive the patient is while driving are the basic elements on which to make this decision. The latter determination can be achieved by referring the patient to the department of motor vehicles for further testing.

\section{References}

1. Evans DA, Funkenstein HH, Albert MS, Scherr PA, Cook NR, Chown MJ, et al. Prevalence of Alz- heimer disease in a community population of older adults. Higher than previously reported. JAMA 1990;262:2551-6.

2. Donnelly RE, Karlinsky H. The impact of Alzheimer's disease on driving ability: a review. J Geriatr Psychiatry Neurol 1990;3(2):67-72.

3. Haxby JV, Grady CL, Duara R, Schlageter N, Berg G, Rapoport SI. Neocortical metabolic abnormalities precede nonmemory cognitive defects in early Alzheimer's-type dementia. Arch Neurol 1986;43: 882-5.

4. Parasuraman R, Nestor PG. Attention and driving skills in aging and Alzheimer's disease. Hum Factors 1991;33:539-57.

5. Rebok GW, Keyl PM, Bylsma FW, Blaustein MJ, Tune L. The effects of Alzheimer disease on driving-related abilities. Alzheimer Dis Assoc Disord 1994;8:228-40.

6. Kaszniak AW, Keyl PM, Albert MS. Dementia and the older driver. Hum Factors, 1991;33:527-37.

7. Barrett GV, Mihal WL, Panek PE, Sterns HL, Alexander RA. Information-processing skills predictive of accident involvement for younger and older commercial drivers. Indust Gerontol 1977; 4:173-82.

8. Kahneman D, Ben-Ishai R, Lotan M. Relation of a test of attention to road accidents. J App Psychol 1973;58:113-5.

9. Mihal WL, Barrett GV. Individual differences in perceptual information processing and their relation to automobile accident involvement. J Appl Psychol 1976;61:229-33.

10. Owsley C, Ball K, Sloane ME, Roenker DL, Bruni JR. Visual/cognitive correlates of vehicle accidents in older drivers. Psychol Aging 1991;6:403-15.

11. Parasuraman R, Nestor P. Attention and driving. Assessment in elderly individuals with dementia. Clin Geriatr Med 1993;9:377-87.

12. Ball $\mathrm{K}$, Owsley $\mathrm{C}$. Identifying correlates of accident involvement for the older driver. Hum Factors 1991;33:583-95.

13. Drachman DA, Swearer JM. Driving and Alzheimer's disease: the risk of crashes. Neurology 1993;43: 2448-56.

14. Odenheimer GL. Dementia and the older driver. Clin Geriatr Med 1993;9:349-64.

15. Tuokko H, Tallman K, Beattie BL, Cooper P, Wier $\mathrm{J}$. An examination of driving records in a dementia clinic. J Gerontol B Psychol Sci Soc Sci 995;50: S137-81.

16. Graca JL. Driving and aging. Clin Geriatr Med 1986;2:577-89.

17. Hunt L, Morris JC, Edwards D, Wilson BS. Driving performance in persons with mild senile dementia of the Alzheimer type. J Am Geriatr Soc 1993;41: 747-52.

18. Friedland RP, Koss E, Kumar A, Gaine S, Metzler D, Haxby JV, et al. Motor vehicle crashes in dementia of the Alzheimer type. Ann Neurol 1988;24: 782-6.

19. Lucas-Blaustein MJ, Filipp L, Dungan C, Tune L. Driving in patients with dementia.J Am Geriatr Soc 
1988;36:1087-91.

20. Logsdon RG, Teri L, Larson EB. Driving and Alzheimer's disease. J Gen Intern Med 1992;7:583-8.

21. Tuokko H, Tallman K, Beattie BL, Cooper P, Weir $\mathrm{J}$. An examination of driving records in a dementia clinic. J Gerontol B Psychol Sci Soc Sci 1995;50: S173-81.

22. Johansson K, Bogdanovic N, Kalimo II, Winblad B, Viitanen M. Alzheimer's disease and apolipoprotein $E$ epsilon 4 allele in older drivers who died in automobile accidents. Lancet 1997;349:1143-4.

23. O'Neill D. Physicians, elderly drivers, and dementia. Lancet 1992;339:41-3.

24. Shemon K, Christensen R. Automobile driving and dementia. Gerontologist 1989;29:10A.

25. Gilley DW, Wilkson RS, Bennett DA, Stebbins GT, Bernard BA, Whalen ME, et al. Cessation of driving and unsafe motor vehicle operation by dementia patients. Arch Intern Med 1991;151:941-6.

26. Deiter P, Wolf S. Driving and Alzheimer's disease. Ann Neurol 1990;28:591-92.

27. Deiter, P, Wolf, S. Driving and AD (letter). Ann Neurol 1990;28:591-92.

28. Drachman DA. Who may drive? Who may not? Who shall decide? Ann Neurol 1988;24:787-8.

29. Reuben DB. Assessment of older drivers. Clin Geriatr Med 1993;9:449-59.

30. Sbordone RJ, Long, CJ, editors. Ecological validity of neuropsychological testing. Delray Beach, Fla: St. Lucie Press, 1996.

31. Fitten LJ, Perryman KM, Wilkinson CJ, Little RJ, Burns MM, Pachana N, et al. Alzheimer and vascular dementias and driving. A prospective road and laboratory study. JAMA 1995;273:1360-5.

32. Atari research driving simulator. Milpetus, Calif: Atari, 1990.

33. Cox DJ, Gonder-Frederick LA, Clarke WL. Driving decrements in type I diabetes during moderate hypoglycemia. Diabetes 1993;42:239-43.

34. Quillian WC, Cox DJ, Gonder-Frederick LA, Driesen NR, Clarke WL. Reliability of driving performance during moderate hypoglycemia in adults with IDDM. Diabetes Care 1994;17:1367-8.

35. Cox DJ, Quillian WC, Gressard C, Westerman PS,
Gonder-Frederick LA, Canterbury RJ. The effects of blood alcohol levels on driving variables in a highrisk population: objective and subjective measures. J Alcohol Drug Educ 1995;40(3):84-98.

36. Quillian WC, Cox DJ, Kovatchev B, Phillips C. The effects of age and legal intoxication on simulated driving performance, awareness, and self-restraint. Age Ageing, in press.

37. Szlyk JP, Severing K, Fïshman GA. Peripheral visual field loss and driving performance. Washington, DC: AMA Foundation for Traffic Safety Research Reports, 1991.

38. Szlyk JP, Alexander KR, Severing K, Fishman GA. Assessment of driving performance in patients with retinitis pigmentosa. Arch Ophthalmol 1992;110: 1709-13.

39. Szlyk JP, Brigell M, Seiple IV. Effects of age and hemianoptic visual field loss on driving. Optom Vis Sci 1993;70:1031-7.

40. Szlyk JP, Fishman GA, Severing K, Alexander KR, Viana $M$. Evaluation of driving performance in patients with juvenile macular dystrophies. Arch Ophthalmol 1993;111:207-12.

41. Szlyk JP, Seiple IV, Viana M. Relative effects of age and compromised vision of driving performance. Hum Factors 1995;37:430-6.

42. Guerrier JH, Manivannan P, Pacheco A, Wilkie FL. The relationship of age and cognitive characteristics of drivers to performance of driving tasks on an interactive driving simulator. Proceedings of the 39th annual meeting of the Human Factors and $\mathrm{Er}$ gonomics Society. San Diego: Human Factors and Ergonomics Society, 1995:172-6.

43. Cox DJ, Kovatchev BP, Kiernan B, Quillian W, Guerrier J, George C. Evaluation of older driver's performance employing driving simulator. In Kemeny A, editor. DSC 97 - Driving Simulation Conference. Paris: ETNA, TEKNEA, 1997.

44. Folstein MF, Folstein SE, McHugh PR. Mini-mental state. A practical method for grading the cognitive state of patients for the clinician. J Psychiatr Res 1975;12:189-98.

45. Diagnostic and statistical manual of mental disorders: DSM-III-R. 3rd ed, revised. Washington, DC: American Psychiatric Association, 1987. 